\title{
INVESTIGACIÓN
}

Recibido: 20/11/2019 --- Aceptado: 24/02/2019 --- Publicado: 15/12/2020

\section{FOMENTO DEL MOBILE LEARNING EN EDUCACIÓN ALREDEDOR DE LA ÚLTIMA DÉCADA. UN ESTUDIO DE CASO EN ESPAÑA TRAVÉS DE UNA SELECCIÓN DE APORTACIONES}

\section{Promotion of Mobile Learning in education around the last decade. A case study in Spain through a selection of contributions}

David Mascarell Palau1. Universitat de València. España.

David.Mascarell.Palau@uv.es

\section{RESUMEN}

En la actualidad educativa las TIC han propiciado de manera inevitable el uso de los dispositivos móviles en el aula y en concreto del teléfono móvil como herramienta educativa. Desde hace años se desarrolla literatura al respecto y se han llevado a cabo proyectos y actividades educativas que lo promocionan. Se trata de una de las metodologías educativas emergentes que ha ido en aumento paulatinamente, se va integrando en la escuela tímidamente y, en algunos casos, con ciertos prejuicios sobre su uso. El siguiente escrito aborda el desarrollo del Mobile Learning o Aprendizaje en Movilidad en la segunda década del siglo XXI en el Estado Español. Damos cuenta de la divulgación científica acontecida, según algunos autores, y en concreto de tesis doctorales publicadas en los últimos años. Analizamos el apoyo a este nuevo paradigma educativo a través de organismos como la Unesco, Fundación Telefónica, así como mediante reuniones científicas y Simposios Internacionales sobre las perspectivas de implementación. También revisamos los datos más destacados respecto al Informe Horizon, centrándonos principalmente en la educación superior. La metodología utilizada en el presente trabajo ha sido el análisis de contenido desde la perspectiva investigadora cualitativa, a partir de la descripción e interpretación de las fuentes consultadas. Finalmente, ofrecemos un punto de vista sobre cuál es en el momento actual la aportación educativa de los dispositivos móviles dentro de la metodología Mobile Learning.

PALABRAS CLAVE: Mobile Learning - organismos educativos - proyectos educativos - dispositivos móviles - TIC - smartphones.

\footnotetext{
${ }^{1}$ David Mascarell Palau. Graduado en Artes Aplicadas al Diseño y Licenciado en Bellas Artes con premio al mejor expediente académico de carrera, 2009. Máster Universitario del Profesorado de Educación Secundaria y Máster Universitario de Didácticas Específicas. Doctor en Didácticas de las Artes Visuales. Miembro del grupo de Investigación en Pedagogías Culturales, Creari (GIUV2013103).
} 
Fomento del Mobile Learning en educación alrededor de la última década. Un estudio de caso en España través de una selección de aportaciones

\section{ABSTRACT}

At present, ICTs have inevitably led to the use of mobile devices in the classroom and in particular the mobile phone as an educational tool. Literature has been developed for years and educational projects and activities that promote it have been carried out. It is one of the emerging educational methodologies that has been increasing gradually, it is integrated timidly into the school and, in some cases, with certain prejudices about its use. The following paper deals with the development of Mobile Learning or Mobility Learning in the second decade of the 21st century in the Spanish State. We give an account of the scientific dissemination that has taken place, according to some authors, and specifically of doctoral theses published in recent years. We analyze support for this new educational paradigm through organizations such as Unesco, Fundación Telefónica, as well as through scientific meetings and International Symposiums on the prospects for implementation. We also review the most prominent data regarding the Horizon Report, focusing mainly on higher education. The methodology used in this work has been the analysis of content from the qualitative research perspective, based on the description and interpretation of the sources consulted. Finally, we offer a point of view on what is currently the educational contribution of mobile devices within the Mobile Learning methodology.

KEY WORDS: Mobile Learning - educational organizations - educational projects mobile devices - ICT - smartphones.

\section{PROMOÇÃO DO MOBILE LEARNING NA EDUCAÇÃO POR VOLTA DA ÚLTIMA DÉCADA. UM ESTUDO DE CASO NA ESPANHA ATRAVÉS DE UMA SELEÇÃO DE CONTRIBUIÇÕES}

\section{RESUMEN}

$\mathrm{Na}$ atualidade educativa as TIC têm promovido de forma inevitável o uso dos dispositivos móveis nas aulas e em específico o telefone celular como ferramenta educativa. Por anos se desenvolve literatura ao respeito e foram realizados projetos e atividades educativas que o promovem. Trata-se de uma das metodologías educativas emergentes que tem aumentado gradualmente, que vai se integrando na escola timidamente e, em alguns casos, com certos preconceitos sobre seu uso. A seguinte escrita aborda o desenvolvimento do Mobile Learning o Aprendizado em Mobilidade na segunda década do século XXI no Estado Espanhol. Mostramos a divulgação científica que aconteceu, segundo alguns autores, e concretamente em tese de doutorado publicadas nos últimos anos. Analisamos o apoio a este novo paradigma educativo através de órgãos como a Unesco, Fundação Telefônica, assim como através de reuniões científicas e Simpósios Internacionais sobre as perspectivas de implementação. Também verificamos os dados mais destacados no que diz respeito ao Informe Horizon, concentrado principalmente na educação superior. A metodologia utilizada no presente trabalho foi a análise de conteúdo desde a perspectiva de pesquisa qualitativa, a partir da descrição e interpretação das fontes 
Fomento del Mobile Learning en educación alrededor de la última década. Un estudio de caso en España través de una selección de aportaciones

consultadas. Finalmente, oferecemos um ponto de vista sobre qual é o momento atual da aportação educativa dos dispositivos móveis dentro da metodologia Mobile Learning.

PALAVRAS CHAVE: Mobile Learning - órgãos educativos - projetos educativos dispositivos móveis - TIC - smartphones.

\section{Como citar el artículo:}

Mascarell Palau, D. (2020). Fomento del Mobile Learning en educación alrededor de la última década. Un estudio de caso en españa través de una selección de aportaciones. [Promotion of Mobile Learning in education around the last decade. A case study in Spain through a selection of contributions].Vivat Academia. Revista de Comunicación, 153, 73-97. doi: https:// doi.org/10.15178/va.2020.153.73-97 Recuperado de http://www.vivatacademia.net/index.php/vivat/article/view/1213

\section{INTRODUCCIÓN}

En este apartado incluimos, en primer lugar, en qué situación se encuentra el $M$ Learning en el momento educativo en que se aborda el presente análisis. Hemos realizado una revisión de diferentes estudios publicados en el Estado Español en relación a la implementación de esta metodología en el entorno de la educación formal. Las contribuciones de otros autores (Brazuelo \& Gallego, 2011) que han trabajado sobre las publicaciones realizadas acerca del Mobile Learning años atrás, nos sirven como base y punto de partida a la presente contribución. Con el arraigo progresivo de la tecnología portable y la mejora en la conectividad se aprecia un aumento paralelo en las experiencias y publicaciones sobre M-Learning, principalmente en el último quinquenio.

En el Estado Español distinguimos autoridades en este tema, entre las que destacan: Brazuelo y Gallego, (2011); Camacho, M. (2011); Castaño, C. y Cabero, J. (2013); Santiago, R., Amo, D., Díez, A. (2014); Santacana, J., y Coma, L. (coords.) (2014). Por otra parte, en el extranjero, señalamos a: Sharples, M., Taylor, J. \& Vavoula, G. (2005); Laouris, Y. \& Eteokleous, N. (2005); Traxler, J. (2009); Rinaldi, M. (2011).

\subsection{Mobile learning en educación}

La realidad del M-Learning no sería posible sin el elemento tecnológico que se ha expandido de manera más acelerada, arraigándose estoicamente en la sociedad actual: el teléfono móvil inteligente. El informe del INE en lo referente a la penetración de la telefonía móvil en los hogares españoles en 2009, afirmaba que el 93,5\% disponían de este servicio, superando el 80,3\% de hogares con teléfono fijo. En cambio, el mismo informe en su propuesta de 2018, analiza que el 97,4\% dispone de teléfono móvil en sus hogares y el 77,6\% de telefonía fija. En el ámbito mundial la Unesco confirma la existencia de más de seis mil millones de abonados. A estas alturas se cifra en superior la cantidad de usuarios que acceden en la red vía un teléfono móvil que desde un ordenador. Según la UIT, organismo especializado de 
Fomento del Mobile Learning en educación alrededor de la última década. Un estudio de caso en España través de una selección de aportaciones

las Naciones Unidas para las TIC, el número de conexiones a Internet en las 200 ciudades más grandes del mundo se multiplicará por 30 en 2016 . Unos 2700 millones de personas navegan por la red y, de ellas, 2100 millones lo hacen por la banda ancha con móvil. Estos datos apoyan y confirman nuestro interés por estudiar la introducción del aprendizaje en movilidad en la educación. Todavía más si tenemos en cuenta, citando datos de Ofcom (regulador independiente para las industrias de comunicación en Reino Unido), que un 99\% de personas entre 15 y 24 años (intervalo en que se incluye un alto porcentaje de nuestros estudiantes) dispone de un teléfono móvil. Se trata de la tasa de penetración más elevada en cualquier grupo de edad. En 2011, el Observatorio de la Formación en Red, SCOPEO, abordaba el Monográfico: M-Learning en España, Portugal y America Latina. Este, concluía que los teléfonos móviles (y dispositivos análogos) ejercen una gran influencia no solo sobre los paradigmas de aprendizaje sino principalmente en todo el repertorio de agentes y parámetros relacionados. Por tanto, habrá que atender en buena medida las cuestiones sociológicas y educativas, no solo las tecnológicas. En España el $M$ Learning se encontraba en 2012 en una fase incipiente, pero en auge en el ámbito educativo general y, en concreto, en el universitario. El Informe Horizon ya en 2012 la consideraba una de las metodologías que más impacto tendría en los años sucesivos. Los estudios que anualmente realiza el observatorio Cegos (firma global de servicios de consultoría, formación y selección que opera en más de 28 países de Europa, América y Asia) pueden servirnos de referencia para contrastar datos estadísticos en relación a la formación de los trabajadores europeos en 2013 y las metodologías empleadas. El último estudio muestra que los métodos evolucionan rápidamente. Si en 2010 únicamente un 8\% recibió formación mediante el terminal móvil, tres años más tarde ya eran un 35\% los empleados que se habían formado con esta modalidad.

Cómo se desprende de estas informaciones estamos ante un campo emergente que, desde nuestro posicionamiento como docentes del arte, es necesario implementar. Educativamente hablando si algo implica en el presente es cambio. La tecnología está destinada a cambiar los paradigmas educativos. Se perfila esta como una magnífica oportunidad para abandonar pedagogías tóxicas, ${ }^{2}$ siguiendo la terminología de María Acaso (2009) y actualizar las prácticas de manera coherente con el desarrollo social y tecnológico (Mascarell, 2012). Es impensable concebir una Educación que da la espalda a la realidad hipervisual que nos rodea.

Son las exigencias de la Sociedad del Conocimiento las que imponen las tendencias actuales en la educación. Así se refleja en el proceso de Bolonia que requiere introducir una serie de cambios significativos en la estructura curricular, prestando especial atención a las TIC y, como no, a nuevas estrategias pedagógicas. El uso de las TIC como herramienta transversal es una interesante apuesta como medio en la aplicación del currículo en las aulas (Botella, Hurtado y Ramos, 2019). En el I Simposio Internacional sobre aprendizaje móvil que tuvo lugar en Córdoba

\footnotetext{
2 Terminología que acuña María Acaso para designar métodos de enseñanza nocivos para los estudiantes, que contribuyen a mermar el interés, la motivación y el resultado del aprendizaje.
} 
Fomento del Mobile Learning en educación alrededor de la última década. Un estudio de caso en España través de una selección de aportaciones

enopinamos febrero de 2014, se expusieron las consideradas como las diez tendencias educativas actuales en opinión de Susan Patrick (presidenta y directora ejecutiva de INACOL, Asociación Internacional para el Aprendizaje en línea). Se comprueba que se ajustan a todo aquello que comporta la enseñanza en movilidad. De hecho, prestamos atención a la décima propuesta:

1. Aprendizaje por competencias.

2. Personalización de las estrategias de aprendizaje.

3. E-Folio. Estudio o mapa personalizado de aprendizaje.

4. Aprendizaje digital.

5. Blended Learning (semi-presencial). Control de su propio aprendizaje.

6. Puentes entre aprendizaje formal e informal.

7. Aprendizaje adaptativo a las necesidades e intereses particulares.

8. Reconocimiento de esfuerzos-premio.

9. Conexión recursos comunitarios. El profesor como "entrenador".

10. Mobile Learning. Metodología que reúne todas las tendencias anteriores.

Las repercusiones educativas del aprendizaje en movilidad quedan especificadas en cada una de las tendencias citadas. Si tratamos de resumir y concluir cuál es el punto clave nos remitimos directamente al contexto. Vavoula y Sharples (2008) nos confirman que el aprendizaje móvil no es solamente aquella facilidad gracias a las tecnologías móviles, sino que implica "procesos de llegar a conocer a través de conversaciones y exploraciones a través de múltiples contextos" (Vavoula y Sharples, 2008: 1). El aprendizaje móvil permite contextualizar el proceso en el sentido más ancho. La contextualización se efectuará a diferentes niveles y, en este sentido, se entenderá como sinónimo de personalización del proceso de enseñanza-aprendizaje, en la que el estudiante participa directamente $y$, en la que tiene un peso extraordinario la posibilidad de movilidad. Defendemos esta opción como una plataforma ideal para complementar la formación, gestionar el conocimiento y apoyar al alumnado, independientemente del tipo de modalidad implementada. Ahora bien, da paso a un nuevo escenario, sin pasar por alto que de este modo empiezan a borrarse las fronteras entre el aprendizaje formal y el informal. Instruirse a través de la Web 2.0 es también un aprendizaje informal, ahora con la web 5.0, las personas aprenden mediante el intercambio y la colaboración en entornos virtuales. Se trata de una cuestión que los estudiosos del tema no consideran una consecuencia negativa. Jay Cross (2006), reconocido mundialmente como líder en Aprendizaje Informal, destaca que el aprendizaje informal es considerado como más personalizado. El estudiante puede elegir el tema y en muchas ocasiones decide cómo y dónde aprenderlo. Este aprendizaje se puede ejercer solo con otras personas y en contextos no formales educativamente. Tenemos que ser conscientes que gran parte de situaciones de adquisición de conocimiento se producen fuera del ámbito académico, de manera informal. ¿Por qué no llevar también las acciones educativas formales a espacios externos al aula favoreciendo el aprendizaje en contextos reales? 
Fomento del Mobile Learning en educación alrededor de la última década. Un estudio de caso en España través de una selección de aportaciones

\section{OBJETIVO}

Este estudio ha incidido en la pesquisa de recopilar, analizar y referir documentos relevantes sobre el Mobile Learning por determinadas instituciones e informes, que avalan su aplicación educativa y derivan en su evolución.

\section{METODOLOGÍA}

La metodología llevada a cabo se basa en el análisis de información o de contenido de carácter cualitativo. Este método implica la revisión de literatura relevante, la extracción de la información para el posterior análisis y evaluación de la misma. El resultado implica la recopilación de ideas destacadas de los documentos, con la finalidad de expresar el resultado del contenido sin indeterminaciones (Solís Hernández, 2003). Así mismo, la descripción y la interpretación de la literatura a análisis se convierte en la esencia de la investigación (Bardín, 2002).

En esta línea, se ha llevado a cabo la prospección de literatura significativa. Tras un análisis previo, se ha descartado parte de la información y se ha seleccionado aquella más afín a las pretensiones del trabajo, centrada en la evolución sobre la literatura de la vertiente educativa del Mobile Learning y el apoyo de ciertas instituciones relevantes al planteamiento de aprender en movilidad.

Debido a la amplia extensión que podría abarcar la propuesta y a las limitaciones evidentes de este trabajo, hemos recabado brevemente los aspectos de mayor interés y su evaluación.

\subsection{Análisis de la literatura convergente en el fomento del mobile learning.}

a. Literatura convergente en relación a la producción científica y tesis doctorales defendidas sobre Mobile Learning en el estado español entre los años 2009 y 2017.

En cuanto a experiencias educativas M-Learning desde el campo de las artes, las más significativas a nivel mundial paradójicamente han sido enmarcadas en ámbitos de conocimiento alejados de la propiamente dicha educación en artes, siendo pocos los referentes con validez científica a los que podemos acudir. No obstante, consideramos que, desde la perspectiva visual, la producción de imágenes a través de la captación con la cámara de los teléfonos móviles, colabora en el aprendizaje de las artes visuales. La finalidad de realizar una lectura crítica y un análisis reflexivo de la producción visual, en el marco de un planteamiento didáctico, ayuda a promover el pensamiento divergente desde un punto de vista creativo. Actividades educativas elaboradas mediante imágenes generadas por los estudiantes, futuros maestros, a partir de problemáticas sociales, resultan de especial interés para favorecer la adquisición del compromiso social en el alumnado en tanto que agentes sociales. (Mascarell, 2013, 2017 y 2019). 
Fomento del Mobile Learning en educación alrededor de la última década. Un estudio de caso en España través de una selección de aportaciones

Dentro del contexto estatal son Brazuelo y Gallego algunos de los autores de referencia nacional que han realizado aportaciones a la divulgación metodológica del aprendizaje en movilidad. En el año 2014 publican, en Educar em Revista (Brasil), un artículo científico donde se hace patente la situación del Mobile Learning en el Estado Español a partir de un estudio de revisión descriptiva de la producción científica nacional entre 2009 y 2013. Los resultados denotan un intensificado interés por la instauración de principios teóricos y la experimentación para la incorporación de las tecnologías móviles en la educación. Según citan los propios autores de la producción científica un $15 \%$ corresponde a tesis doctorales; un 2,5\% a libro o eBooks; para capítulos de libros un $11 \%$; el $44,5 \%$ son artículos de revistas y el $41 \%$ artículos de acontecimientos científicos como actas de congresos.

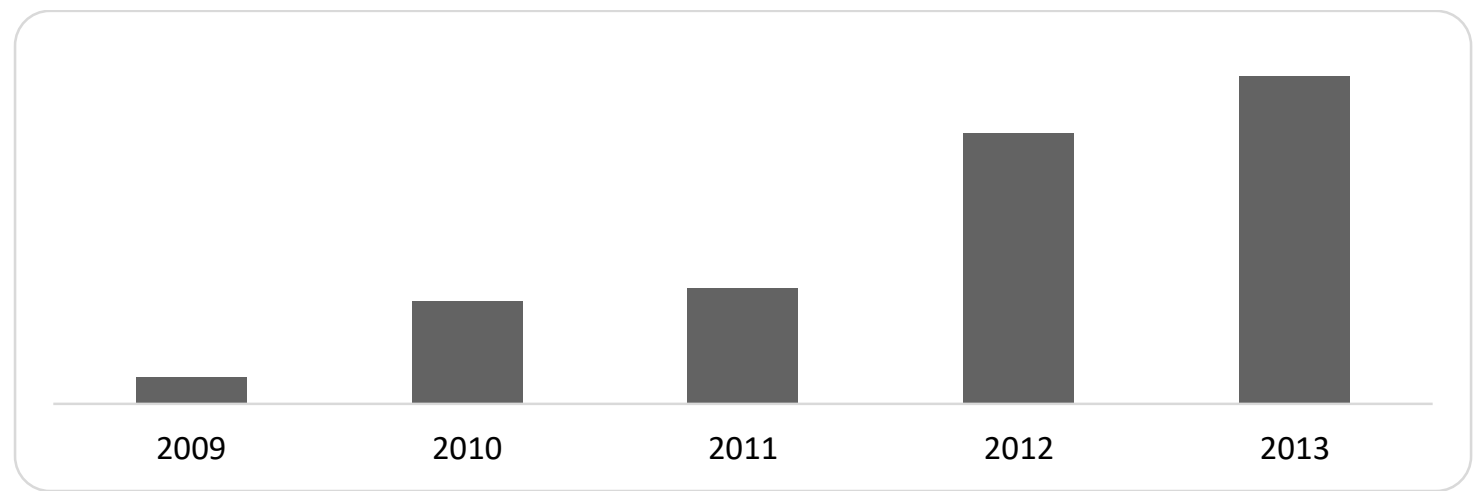

Gráfico 1: Evolución sobre la producción científica total sobre el Mobile Learning, entre 2009 y 2013, en el Estado Español.

Fuente: Brazuelo y Gallego (2014).

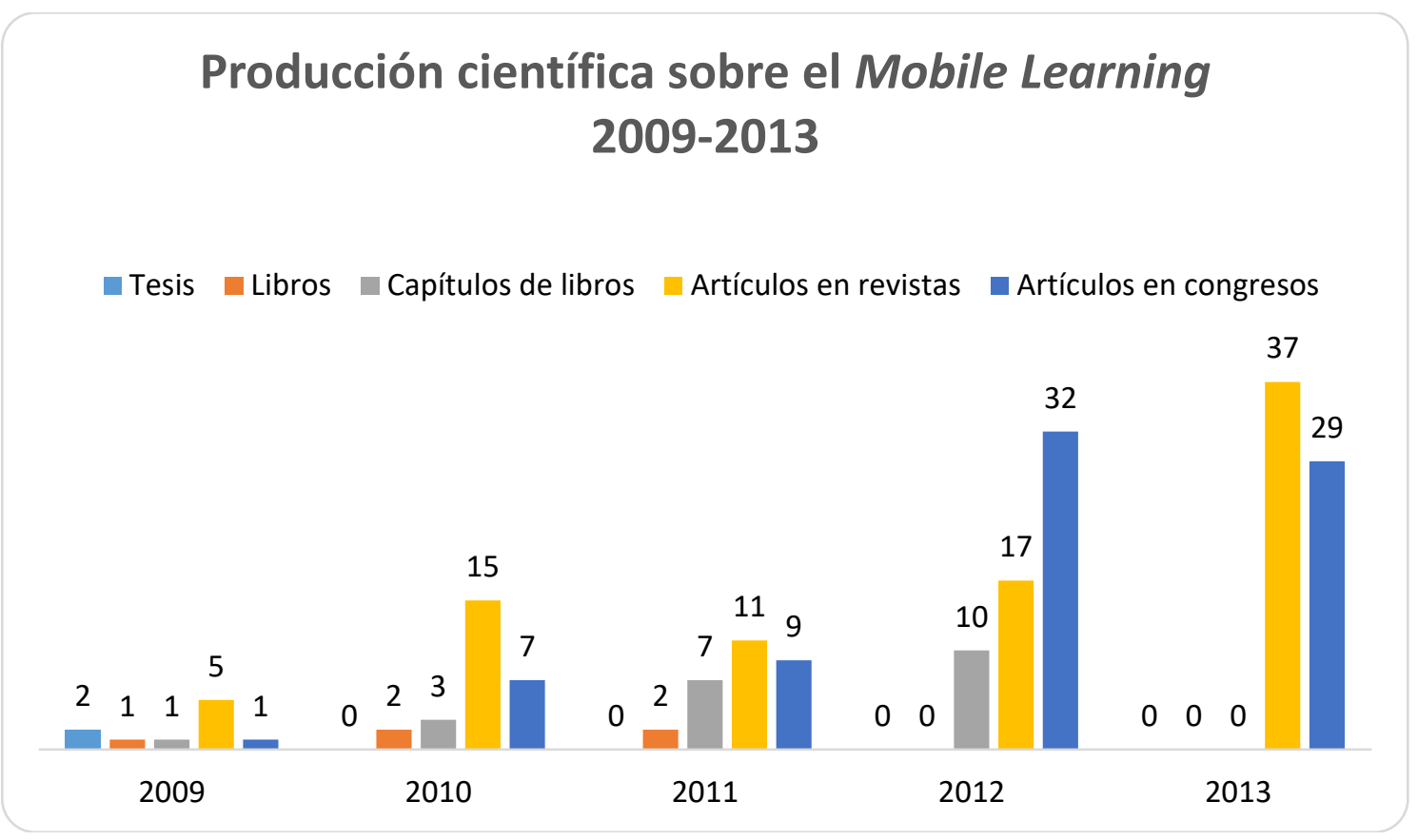

Gráfico 2. Producción científica detallada sobre el Mobile Learning entre 2009-2013 al Estado Español.

Fuente: Brazuelo y Gallego (2014). 
Fomento del Mobile Learning en educación alrededor de la última década. Un estudio de caso en España través de una selección de aportaciones

Las indagaciones realizadas por Brazuelo y Gallego permiten clasificar, en otra tabla (Tabla 3) los ejes temáticos de producción científica en Mobile Learning. Comprobamos que es el teléfono móvil el elemento tecnológico con el que se empieza a implementar la fundamentación teórica en el año 2009; pero dos años más tarde, en 2011, su uso resulta ya ampliamente superado por las tabletas digitales. En cuanto a experiencias desarrolladas la mayor parte se centra claramente en las apps o aplicaciones, que disfrutan de gran popularidad social, y la expansión de las cuales ha sido espectacular desde 2013, seguidas por los estudios centrados en realidad aumentada.

Tabla 1. Ejes temáticos del contenido de la producción científica del Mobile Learning al Estado Español (2009-2013).

\begin{tabular}{lllllll}
\hline $\begin{array}{l}\text { Ejes temáticos de la producción científica } \\
\text { sobre Mobile Learning en el Estado } \\
\text { Español por años }\end{array}$ & $\mathbf{2 0 0 9}$ & $\mathbf{2 0 1 0}$ & $\mathbf{2 0 1 1}$ & $\mathbf{2 0 1 2}$ & $\mathbf{2 0 1 3}$ & Total \\
\hline $\begin{array}{l}\text { Fundamentación teórica y divulgación } \\
\text { Teléfono móvil/smartphone }\end{array}$ & 2 & 13 & 11 & 25 & 24 & 76 \\
\hline Tabletas digitales/iPad & 2 & 4 & 3 & 3 & 3 & 14 \\
\hline SMS & 0 & 0 & 2 & 11 & 11 & 24 \\
\hline Podcast & 0 & 1 & 0 & 0 & 0 & 1 \\
\hline Redes sociales & 1 & 2 & 6 & 1 & 4 & 14 \\
\hline $\begin{array}{l}\text { Experiencias y estudios de caso de } \\
\text { implementación Realidad aumentada }\end{array}$ & 1 & 1 & 0 & 3 & 2 & 7 \\
\hline Códigos QR & 0 & 1 & 3 & 7 & 7 & 18 \\
\hline Apps & 0 & 0 & 1 & 5 & 3 & 9 \\
\hline TOTALES ANUALES & 0 & 1 & 0 & 6 & 20 & 27 \\
\hline
\end{tabular}

Fuente: Brazuelo y Gallego (2014).

En resumen, a pesar del progresivo aumento en la incorporación tecnológica de los dispositivos portables al ámbito educativo, nos encontrábamos ante un fenómeno incipiente, pero en evolución constante en cuanto a estudios e investigaciones al respeto. En ese momento cronológico la producción científica no era proporcional al impacto social y educativo que ha supuesto esta derrama tecnológica pero sí que resultaba un camino con una amplia perspectiva M-Learning.

Por otro lado, destacamos un estudio de análisis de la investigación doctoral sobre Mobile Learning en España, a cargo de los autores: Hinojo, F., Aznar, I., y Romero, J., (2018). Es de interés la recopilación de estudios científicos nacionales, en este caso tesis doctorales, sobre esta temática vinculada a la educación. La publicación da cuenta del número de veintidós tesis doctorales defendidas en el estado español entre 2011 y 2017. El objetivo es divulgar el impacto real de los dispositivos móviles en el aprendizaje de los estudiantes de diferentes niveles educativos. Entre los 
Mascarell Palau, D.

Fomento del Mobile Learning en educación alrededor de la última década. Un estudio de caso en España través de una selección de aportaciones

resultados, resalta la variedad de ámbitos de enseñanza que son objeto de interés de la investigación doctoral en España, la diversidad de objetivos en la investigación sobre aprendizaje móvil y los métodos utilizados para obtener la información.

Tabla 2. Número de tesis sobre M-Learning defendidas en el estado español entre 2011 a 2017 por universidad de procedencia.

$\begin{array}{cl}\begin{array}{c}\text { Tesis defendidas M-Learning } \\ \text { en el Estado Español }\end{array} & \text { Universidad de procedencia } \\ 3 & \text { Universidad de Granada } \\ 2 & \text { Universidad de La Laguna } \\ 2 & \text { Universitat de Girona } \\ 2 & \text { Universidad Nacional de Educación a Distancia (UNED) } \\ & \text { de España } \\ 2 & \text { Universidad de Salamanca } \\ 1 & \text { Universidad de Alcalá } \\ 1 & \text { Universitat Politècnica de Cataluña } \\ 1 & \text { Universitat Rovira i Virgili } \\ 1 & \text { Universitat Politècnica de València } \\ 1 & \text { Universidad de Murcia } \\ 1 & \text { Universidad de Alicante } \\ 1 & \text { Universidad de Castilla-La Mancha } \\ 1 & \text { Universidad de Valladolid } \\ 1 & \text { Universidad Complutense de Madrid } \\ 1 & \text { Universidad de Extremadura } \\ & \text { Universitat de València }\end{array}$

Fuente: Elaboración propia, a través de los datos de Hinojo, Aznar y Romero (2018).

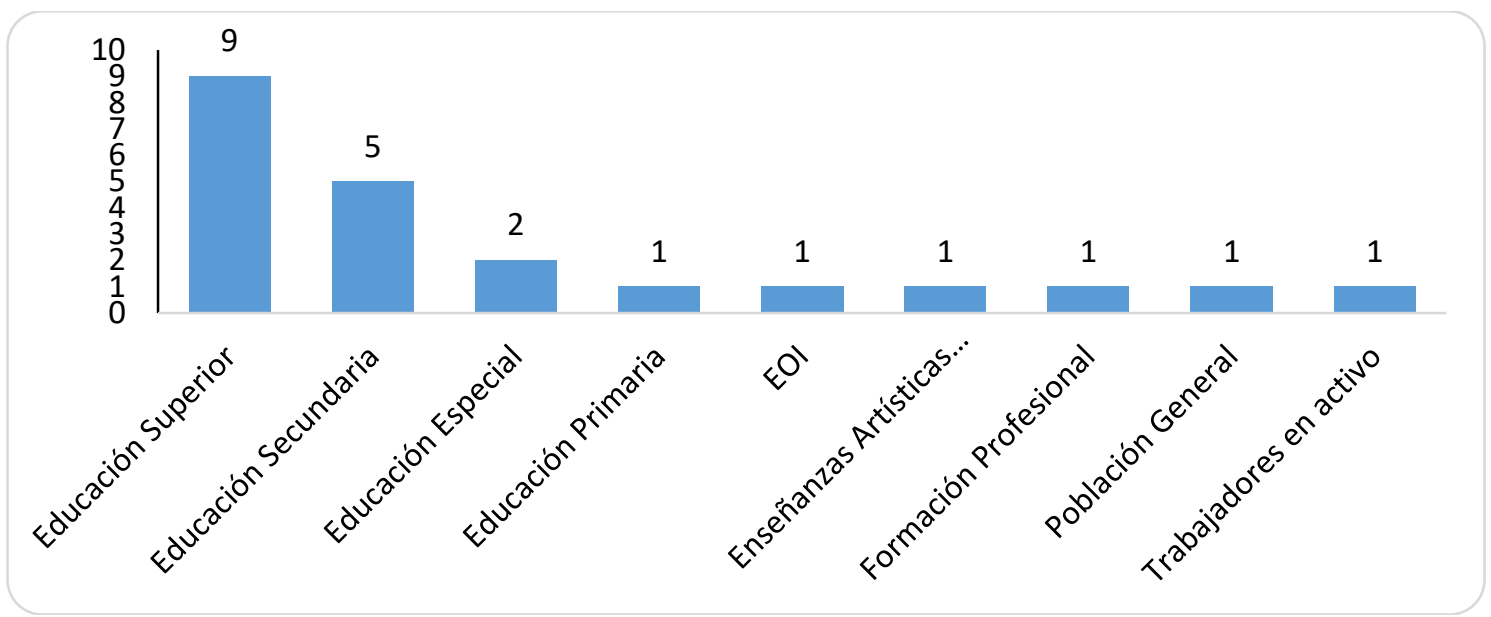

Gráfico 3. Contexto de aplicación donde las tesis doctorales sobre Mobile Learning defendidas en España.

Fuente: Hinojo, Aznar y Romero (2018). 
Fomento del Mobile Learning en educación alrededor de la última década. Un estudio de caso en España través de una selección de aportaciones

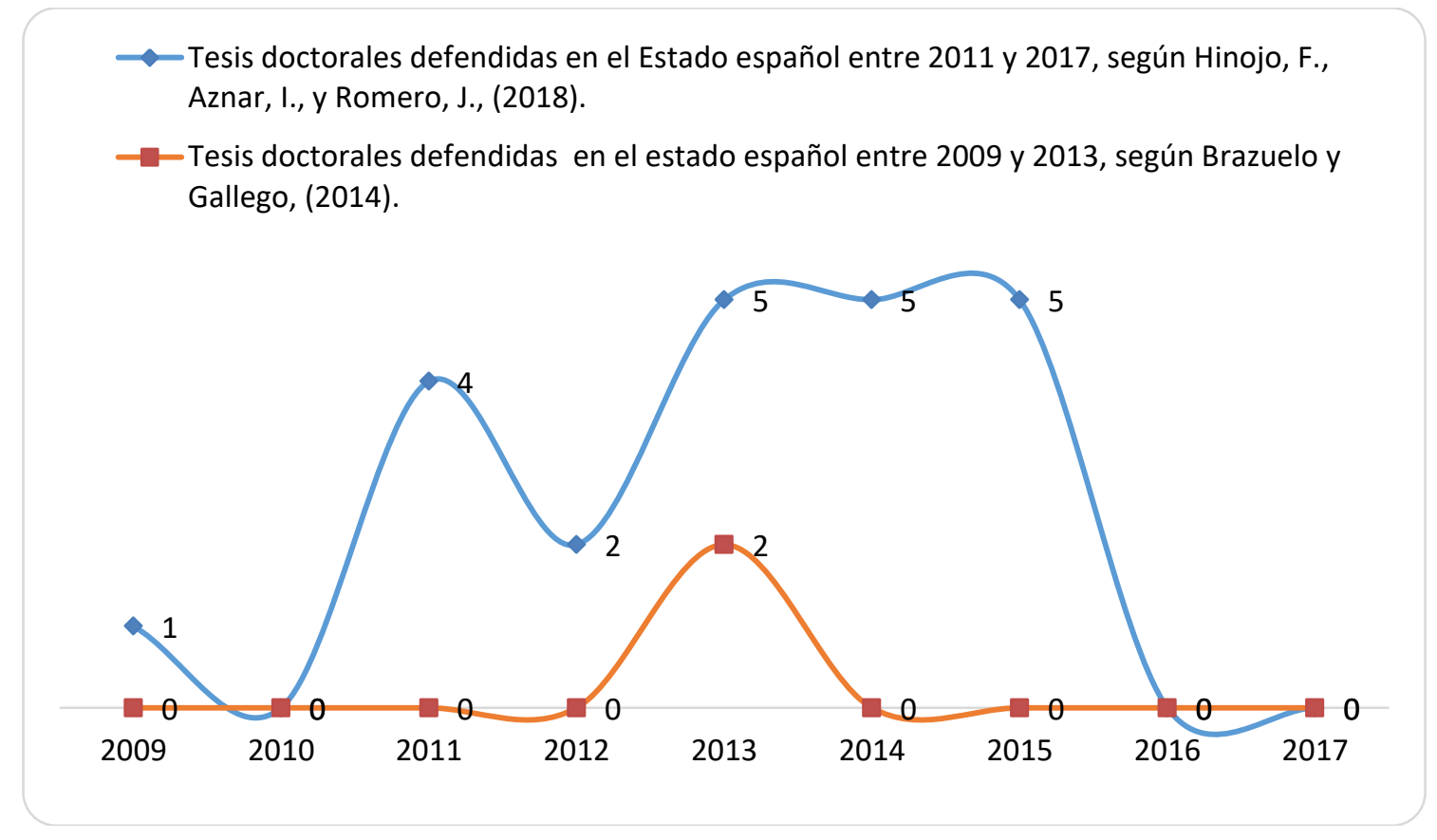

Gráfico 4. Comparativa por años sobre las defensas de tesis doctorales sobre el Mobile Learning defendidas en el estado español desde 2009 a 2017.

Fuente: Elaboración propia.

a) el uso de los dispositivos móviles mejora el aprendizaje, (b) el Mobile Learning es un tema de interés en el campo de la investigación educativa cuya tendencia va en aumento, (c) actualmente la educación superior es la etapa de prevalencia donde se aplica el aprendizaje móvil y (d) la variabilidad de escenarios de aplicación resalta la riqueza de los dispositivos móviles en la mejora educativa. Hinojo, Aznar y Romero, (2018: 171).

Los mismos autores del estudio además hacen alusión a la apreciación de distintas líneas de investigación sobre tesis doctorales en nuestro país acerca de Mobile Learning: mejora del aprendizaje, desarrollo de competencias, evaluación, experiencia del usuario, desarrollo de juegos, percepción sobre su aplicación y efecto de los dispositivos móviles.

La investigación de diferentes acciones divulgativas, que por varias vías tienen lugar o se desarrollan recientemente en España, a cargo de instituciones de referencia pedagógica, nos permitirá una aproximación a la realidad por la apuesta del $M$ Learning en el espacio educativo próximo. Entre los diferentes acontecimientos que desde 2014 se han celebrado consideramos oportuno hacer referencia a los simposios Internacionales sobre Mobile Learning y al Mobile Word Congress 2015.

A continuación, aportamos un breve resumen de los Simposios Internacionales sobre Mobile Learning de los años 2014, 2015 y 2017, a los cuales hemos asistido y aportado contribuciones científicas. 
Mascarell Palau, D.

Fomento del Mobile Learning en educación alrededor de la última década. Un estudio de caso en España través de una selección de aportaciones

\section{B. II Simposio Internacional sobre mLearning 2014}

Título: Repensando la Escuela y el Aprendizaje. Aprendizaje Móvil. Córdoba, 21, 22 y 23 de marzo de 2014.

Organización: Fundación Maecenas Educación y Cultura.

Un interesante referente educativo en cuanto al uso educativo de los dispositivos móviles. Intervinieron personalidades internacionales del mundo de la educación con vinculaciones tecnológicas. Destacan las temáticas abordadas sobre metodologías como Bring Your Own Device (BYOD) y The Flipped Classroom, experiencias educativas en las que se invierten las dinámicas de trabajo y se potencia el trabajo fuera del aula con el fin de destinar el tiempo de las clases presenciales para el desarrollo de procesos cognitivos más complejos, que favorezcan el aprendizaje significativo. El comité académico concluyó coincidiendo en que las tecnologías pueden asumir el papel de impulsoras de un cambio de escuela; ahora bien, no se tiene que tratar de un cambio únicamente tecnológico sino metodológico. Entre otras aportaciones pueden resultar muy eficaces para la personalización del aprendizaje.

\section{III Simposio Internacional sobre M-Learning 2015}

Título: Diseñando proyectos pedagógicos para el Mobile Learning: Claves para el aprendizaje en la escuela.

Madrid, 13 y 15 de marzo de 2015.

Organización: Fundación Maecenas Educación y Cultura.

Bajo el lema relacionado con el diseño de proyectos para el aprendizaje en movilidad en las escuelas, el II Simposio sobre Mobile Learning concluyó argumentando la necesidad de la escuela de preparar a los estudiantes para acomodarse al constante cambio en que desarrollan sus vidas: entorno social, laboral, El mundo educativo tiene que aplicar esa misma situación de cambio, entre el que destaca el tecnológico, no respondiendo al producto sino en la formación que ofrece, promoviendo la adaptabilidad a un entorno flexible y de continua conexión.

\section{V Simposio Internacional sobre M-Learning 2017}

Título: El Mobile Learning como herramienta para la mejora de elementos clave en la educación: la evaluación.

Valencia, 31 de marzo y 1 y 2 de abril de 2017.

Organización: Fundación Maecenas Educación y Cultura.

Este IV Simposio ha destacado por un carácter eminentemente práctico y aplicado del uso educativo de tecnología móvil. Los artefactos que han centrado casi en exclusiva la atención han sido las tabletas digitales, quedando los smartphones en un plano secundario. Ha supuesto una revisión de las principales metodologías que propician el enfoque centrado en el estudiante, el aprendizaje activo, participativo y productivo. Se apuesta por una utilización eficiente de las tecnologías digitales. Se ha

Vivat Academia. Revista de Comunicación. 15 diciembre 2020 /15 marzo 2021, nº 153, 73-97 
Fomento del Mobile Learning en educación alrededor de la última década. Un estudio de caso en España través de una selección de aportaciones

dejado constancia del protagonismo de las Apps educativas en el proceso de enseñanza-aprendizaje en movilidad, y en su incorporación práctica en el aula. Resulta significativo que buena parte de las aplicaciones propuestas apoyen las estrategias de aprendizaje en la imagen y los multimedia, para incrementar y favorecer la comprensión de los contenidos educativos. Entra en juego el componente visual como un potente recurso facilitador de las habilidades de pensamiento de orden superior.

El hilo conductor del Simposio ha versado en torno la evaluación. Se han presentado y difundido interesantes e innovadoras aplicaciones que no solamente facilitan la tarea al profesorado, sino que tratan de involucrar y hacer partícipe el alumnado en el propio sistema evaluador. Es el caso de la app ClassDojo para los niveles de educación Infantil y Primaria. Las conferencias de los profesores Russell Stannard (University of Warwick y University of Westminster) y Raúl Santiago (Universidad de La Rioja) han incidido en métodos digitales de evaluación. Por un lado, Stannard presentó su pionero y reconocido trabajo sobre la interacción entre docente y discente a través de la copia de pantallas (print screen), creación de podcast o video tutoriales, todo fundamentado en la idea de interacción o feedback. Por otro lado, Santiago aportó una interesante disertación alrededor del aprendizaje adaptativo o personalizado. En él recurre a la gamificación, con el fin de generar actividades, el resultado de las cuales recopila a través de analíticas representativas del aprendizaje individualizado con el objetivo de motorizar la evaluación formativa.

En cuanto a las conclusiones, uno de los puntos más destacados ha sido la importancia de la formación de los docentes en competencias digitales (TICs). Se considera requisito obligatorio integrarlas en el mundo educativo en el futuro más próximo.

Tabla 3. Evolución de las temáticas educativas tratadas en el Simposio Internacional sobre M-Learning de los años 2014, 2015 y 2017.

\begin{tabular}{ll}
\hline \multicolumn{1}{c}{$\begin{array}{c}\text { Simposio Internacional sobre Mobile } \\
\text { Learning (Fundación Maecenas) }\end{array}$} & \multicolumn{1}{c}{ Título } \\
\hline $\begin{array}{l}\text { II Simposio Internacional sobre Mobile } \\
\text { Learning, Córdoba 2014. }\end{array}$ & $\begin{array}{l}\text { Repensando la Escuela y el Aprendizaje. } \\
\text { Aprendizaje Móvil. }\end{array}$ \\
\hline $\begin{array}{l}\text { III Simposio Internacional sobre Mobile } \\
\text { Learning, Madrid 2015. }\end{array}$ & $\begin{array}{l}\text { Diseñando proyectos pedagógicos para el } \\
\text { Mobile Learning: Claves para el aprendizaje } \\
\text { en la escuela. }\end{array}$ \\
\hline V Simposio Internacional sobre Mobile & $\begin{array}{l}\text { El Mobile Learning como herramienta para la } \\
\text { mejora de elementos clave en la educación: la } \\
\text { evaluación. }\end{array}$ \\
\hline
\end{tabular}

Fuente: Elaboración propia. 
Fomento del Mobile Learning en educación alrededor de la última década. Un estudio de caso en España través de una selección de aportaciones

\section{c. Mobile World Congress 2015 y 2019}

Barcelona, del 2 al 5 de marzo de 2015.

Organización: Mobile World Capital Barcelona

Este Congreso que desde el año 2006 acoge Barcelona fomenta que la ciudad acontezca durante cuatro días al año en el principal escaparate mundial de tecnología móvil. En el ámbito educativo aporta el programa mEducation. Desde 2012, mSchool fomenta seminarios dirigidos a la comunidad educativa, ayudando a discentes y docentes a integrar las tecnologías móviles en el aula de manera eficaz mediante materiales actualizados. Según $m S$ chool, la tecnología móvil mejora la colaboración y refuerza el compromiso del estudiante, lo cual incentiva la apertura de nuevas vías de enseñanza y aprendizaje que favorecen la productividad y la empleabilidad. Dentro del programa $m S$ chool se sitúa el seminario Changing Education Together (CET), que este año ha celebrado la segunda edición, focalizada en el uso responsable de los dispositivos móviles en educación y al compartir experiencias de trabajo entre centros educativos que plantean el aprendizaje con tecnología móvil. En la actualidad, 2019 mSchools, con el lema "Una nueva forma de enseñar y aprender". Proporciona en su web material sobre experiencias y aplicaciones educativas dentro de la plataforma mSchools. A la vez, está promocionando el aprendizaje con tecnología móvil en centros educativos de Cataluña. Es en la modalidad de experiencias educativas en el aula con tecnologías digitales, a través de premios de formación continuada en la European Schoolnet en Bruselas y compartirlas con centros educativos europeos.

\section{d. Fundación Telefónica, M-Learning 2013, 2014, 2015, 2016, 2019.}

Consideramos a la Fundación Telefónica otro medio difusor del uso educativo del Mobile Learning, aportando un buen número de experiencias internacionales que contribuyen a la divulgación de esta metodología.

En 2013, Curalia, el portal de la Fundación Telefónica que se dedica a la selección y "curación" de contenidos, metodologías y actividades para el siglo XXI, lanza la "Guia Mobile Learning". El objetivo principal es el fomento de un uso didáctico de los smartphones y orientar a docentes y alumnos en la búsqueda de recursos formativos, que son numerosos, pero están mal organizados en la red. Lo justifican argumentando que los teléfonos inteligentes han transformado el modo que percibimos el mundo e interactuamos en la sociedad, añaden que este tipo de dispositivos supone un complemento didáctico que va a tener un peso fundamental en los procesos de la enseñanza de los próximos años.

En 2014 se realiza una publicación que está inmersa en el Laboratorio Mobile Learning de Fundación Telefónica, titulada: "Laboratorio social. Mobile Learning. Mi móvil al servicio de la comunidad: aprender y compartir más allá del aula". La finalidad es plantear experiencias educativas que se puedan trasladar al aula ejemplificando el uso de la tecnología móvil para el cambio educativo. La intención

Vivat Academia. Revista de Comunicación. 15 diciembre 2020 /15 marzo 2021, n 153, 73-97 
Fomento del Mobile Learning en educación alrededor de la última década. Un estudio de caso en España través de una selección de aportaciones

es fomentar la implicación efectiva del alumnado sobre proyectos significativos, en su propio proceso de aprendizaje mediante el acceso masivo a los dispositivos móviles entre los adolescentes a partir de 12 años.

En 2015, en la web de La Fundación Telefónica, encontramos la sección “Sigue las tendencias educativas" y un apartado dedicado al Mobile Learning con una relación de experiencias educativas recogidas en forma de breves artículos de carácter interdisciplinario: recursos, experiencias, ideas para aprender y enseñar con dispositivos móviles en el aula. Destacamos artículos dedicado a reducir la "brecha digital" en las comunidades rurales.

La tecnología Mobile Learning tiene sentido para los niños que viven en zonas rurales o en áreas sin muchos recursos, incluida la electricidad. Un dispositivo de aprendizaje móvil que puede ser producido en masa, a un precio asequible, junto con un cargador de célula solar, puede ser útil incluso sin la capacidad real de conectarse a Internet. Telefónica Fundación, (2015).

En 2016, se presenta otra aportación con el título: Si lo vives, lo compartes. Cómo se comunican los jóvenes en un mundo digital." Una transformación u oportunidad para el cambio educativo. Se considera el potencial de los dispositivos móviles en el aula para trabajar actividades. Tratan el aprendizaje en red, el uso creativo y libre en proyectos educativos o el trabajar a partir de una App. Por último, señalan que los docentes están llamados a protagonizar este cambio para el continuo crecimiento educativo.

En la actualidad de 2019, La fundación Telefónica se une a la Unesco para coorganizar y coordinar el Mobile Learning Week, la reunión más importante sobre el uso de las TIC en la educación a través de ProFuturo la International Telecommunication Union (ITU) y la startup francesa Skillogs. La temática de referencia es la "Inteligencia artificial en la educación, oportunidades y retos para el desarrollo". Aplicable especialmente a países en desarrollo. Se pretende ayudar a mejorar la educación y la enseñanza a través de la introducción de la IA, analítica de datos para la toma de decisiones basadas en Learning Analitics en los Big Data.

Tabla 4. Resumen de las actividades y publicaciones de la Fundación Telefónica en relación al Mobile Learning. Evolución de diversos años hasta 2019.

\begin{tabular}{cl}
\hline $\begin{array}{l}\text { Fundación Telefónica } \\
\text { Publicaciones más destacables }\end{array}$ & Objetivos \\
\hline “Guia Mobile Learning", 2013. & $\begin{array}{l}\text { Fomentar el uso didáctico de } \\
\text { los smartphones y orientar a docentes y } \\
\text { alumnos en la búsqueda de recursos } \\
\text { formativos, numerosos pero mal organizados } \\
\text { en la red. }\end{array}$ \\
\hline "Laboratorio social. Mobile Learning. Mi & $\begin{array}{l}\text { Plantear experiencias educativas que se } \\
\text { puedan trasladar al aula ejemplificando el }\end{array}$ \\
móvil al servicio de la comunidad: aprender & $\begin{array}{l}\text { uso de la tecnología móvil para el cambio } \\
\text { y compartir más allá del aula", 2014. }\end{array}$
\end{tabular}

Vivat Academia. Revista de Comunicación. 15 diciembre 2020 /15 marzo 2021, n 153, 73-97 
Fomento del Mobile Learning en educación alrededor de la última década. Un estudio de caso en España través de una selección de aportaciones

\begin{tabular}{|c|c|}
\hline "Sigue las tendencias educativas", 2015. & $\begin{array}{l}\text { Recursos, experiencias, ideas para aprender y } \\
\text { enseñar con dispositivos móviles en el aula. }\end{array}$ \\
\hline "Guía Mobile Learning", 2016. & $\begin{array}{l}\text { Transformar o dar oportunidad para el } \\
\text { cambio educativo. Aprendizaje ubicuo y en } \\
\text { red. Uso creativo y libre en proyectos } \\
\text { educativos. }\end{array}$ \\
\hline $\begin{array}{l}\text { Coorganizador y coordinador del "Mobile } \\
\text { Learning Week" de la Unesco, } 2019 .\end{array}$ & $\begin{array}{l}\text { La inteligencia artificial y su capacidad para } \\
\text { mejorar y potenciar el ámbito educativo a la } \\
\text { vez que el desarrollo sostenible en la } \\
\text { educación de calidad (ProFuturo). }\end{array}$ \\
\hline
\end{tabular}

Fuente: Elaboración propia.

\section{e. UNESCO, M-Learning}

La Organización de las Naciones Unidas para la Educación, la Ciencia y la Cultura (UNESCO), asume como una de las cinco funciones principales de su tarea, los estudios prospectivos. Tiene como finalidad contribuir a averiguar formas de educación, ciencia, cultura y comunicación para el mundo del futuro. En este aspecto, se considera el aprendizaje móvil o M-Learning como un moderno método de espaldarazo al proceso de aprendizaje mediante el uso de instrumentos móviles, entre ellos, los teléfonos inteligentes o smartphones. Según esta organización, el aprendizaje móvil se está convirtiendo en una de las soluciones a los problemas que confronta el sector educativo. Por esta razón el programa de actividades de la UNESCO se basa en un número cada vez mayor de iniciativas conjuntas encaminadas a estudiar de qué manera las tecnologías móviles pueden propiciar la consecución de la Educación para Todos (EPT). Entre sus asociados figuran la empresa Nokia y el Departamento de Estado de los Estados Unidos de América. En la propia web de la UNESCO, en el apartado correspondiente a "Las TIC en la educación", "Formación de docentes", encontramos varios subapartados relacionados con el aprendizaje móvil. Destacamos "Publicaciones sobre el aprendizaje móvil". Se trata de una serie de textos que, a modo de directrices, tratan de dar difusión a las políticas de aprendizaje móvil. Dada la importancia que la UNESCO le otorga a este método, dedica anualmente un espacio al mismo, la Mobile Learning Week. La última de las cuales tuvo lugar del 7 al 11 de marzo de 2016 en París, bajo la temática: Innovating for quality, como aprovechar mejor la capacidad, el crecimiento y la accesibilidad de la tecnología móvil para garantizar que todos los estudiantes reciban una educación de gran calidad.

En la semana del Mobile Learning de la UNESCO 2019, ha sido protagonista la "Inteligencia artificial (AI) para el Desarrollo Sostenible". Con el objetivo sobre como las tecnologías vinculadas a la AI tiene la posibilidad de cooperar en la recaudación de datos con el fin de mejorar la calidad y la igualdad en este ámbito. Como desafíos, se pretende conseguir: 
Fomento del Mobile Learning en educación alrededor de la última década. Un estudio de caso en España través de una selección de aportaciones

Tabla 5. Desafíos a conseguir por la UNESCO 2019.

Desarrollar una visión integral de las políticas públicas en materia de IA al servicio del desarrollo sostenible.

Garantizar la utilización equitativa e inclusiva de la IA en la educación.

Preparar a los docentes para una educación dirigida por la IA.

Desarrollar sistemas de datos inclusivos y de calidad.

Reforzar las investigaciones sobre la IA en la educación.

Tomar en consideración las cuestiones éticas y de transparencia en la recopilación, la utilización y la difusión de los datos.

Fuente: Elaboración propia.

Tabla 6. Resumen de los temas tratados por la Unesco en relación a su contribución o vinculación al Mobile Learning desde 2011 a 2019.

\begin{tabular}{ll}
\hline UNESCO & $\begin{array}{l}\text { Incorporación } \\
\text { tecnológica alusiva al Mobile Learning }\end{array}$ \\
\hline $\mathbf{2 0 1 1}$ & $\begin{array}{l}\text { Intercambio de ideas creativas, uso tecnologías móviles. } \\
\text { Publicación del libro: } \\
\text { Experiencias educativas con TIC en el aula del siglo XXI. }\end{array}$ \\
\hline $\mathbf{2 0 1 2}$ & $\begin{array}{l}\text { Aprendizaje móvil para desarrollar una comunidad mundial. } \\
\text {-Desarrollo de directrices políticas para ayudar a los gobiernos aprovechar } \\
\text { tecnologías móviles. }\end{array}$ \\
& $\begin{array}{l}\text {-Explorar tecnologías móviles usarse para apoyar a los maestros y desarrollo } \\
\text { profesional. } \\
\text { (Capacitación docente frente al M-Learning) }\end{array}$ \\
& $\begin{array}{l}\text { Examinar el aprendizaje mediante dispositivos móviles en tanto que contribución } \\
\text { singular y significativa a la consecución de los objetivos de la Educación para } \\
\text { todos. }\end{array}$ \\
\hline $\mathbf{2 0 1 3}$ & $\begin{array}{l}\text { Comprender como las tecnologías móviles pueden contribuir a la formación de } \\
\text { nuevos maestros. }\end{array}$ \\
\hline $\mathbf{2 0 1 4}$ & $\begin{array}{l}\text { Aprovechar la tecnología móvil para mejorar la educación y acelerar el } \\
\text { aprendizaje de mujeres y niñas. }\end{array}$ \\
\hline $\mathbf{2 0 1 5}$ & El papel que tienen las tecnologías móviles en la adopción de MOOCs. \\
\hline $\mathbf{2 0 1 7}$ & $\begin{array}{l}\text { Examinar cómo las nuevas tecnologías y asequibles pueden reforzar la educación } \\
\text { en contextos de emergencia y crisis y ampliar las oportunidades de aprendizaje. }\end{array}$ \\
\hline $\mathbf{2 0 1 8}$ & Habilidades para un mundo conectado. \\
\hline $\mathbf{2 0 1 9}$ & Inteligencia artificial para el desarrollo sostenible y para la educación. \\
\hline
\end{tabular}

Fuente: Elaboración propia.

\section{f. Informe Horizon 2013, 2017 y 2019 en relación al M-Learning}

Este informe publicado por The New Media Consortium, Centro Superior para la Enseñanza Virtual (CSEV) y Virtual Educa, marca las tendencias educativas en tecnologías a corto plazo. En referencia a los dispositivos móviles, en 2013 anunció cambios de enfoques en el aprendizaje en relación a la práctica educativa. En concreto aludía al atractivo de aprovechar las tabletas o los smartphones para conectar 
Fomento del Mobile Learning en educación alrededor de la última década. Un estudio de caso en España través de una selección de aportaciones

el currículum escolar con la vida real de los estudiantes con el fin de aumentar su motivación y desplegar el conocimiento más allá del aula.

Por otro lado, en el informe del Informe Horizon 2017, indicaba que la incorporación del Mobile Learning en la educación superior acontecería a corto plazo, concretamente a un año vista, incluso menos. Lo justificaba atendiendo a que "el aprendizaje móvil o M-Learning permite a los estudiantes acceder a materiales de aprendizaje en cualquier lugar, a menudo a través de múltiples dispositivos" Informe Horizon (2017: 17)

"Y es que los dispositivos móviles se han convertido en portales de acceso y entrada a entornos de trabajo y de aprendizaje personalizados que facilitan la exploración de nuevos temas al ritmo de cada usuario. Por si esto fuera poco, los estudiantes también pueden usar los móviles para poner en práctica las competencias del siglo XXI, incluyendo la comunicación, la colaboración y la creación de contenido. Además, los dispositivos móviles facilitan las oportunidades de interacción docente-alumno". Informe Horizon (2017: 17)

Por último y en la actualidad, el Informe Horizon 2019 tiene las mismas previsiones sobre la incorporación educativa del M-Learning en las aulas de la educación superior que el informe de 2017. Lo reitera, como incorporación del $M$ Learning en un año o menos. En este informe se justifica en referencia a la actual era moderna del aprendizaje móvil provocada por el teléfono inteligente desde hace una década. También alude a que tanto los discentes como los docentes confían actualmente en sus dispositivos como una importante parte de toda la experiencia de aprendizaje. El informe avala que el aprendizaje móvil en la actualidad no se centra únicamente en las Apps sino en la conectividad y las experiencias de aprendizaje en cualquier lugar y cualquier momento. Remarcan la ubicuidad como una ventaja para trabajar experiencias ilimitadas de aprendizaje en muchos países a través del poder de los dispositivos móviles. El aumento del uso de la realidad aumentada (AR), realidad virtual (RV) y realidad mixta (RM) ha permitido que el aprendizaje móvil se convierta en más activo y colaborativo. Por último, sin embargo, destacan la laboriosidad de experiencias en aprendizaje móvil, de la planificación y elaboración en su calidad en estas primeras etapas de adopción.

Tabla 7. Aportamos este resumen retrospectivo recopilatorio alusivo al Mobile Learning que se contemplaron para su futura incorporación educativa en el Informe Horizon desde 2007 a 2019.

$\begin{array}{ll}\begin{array}{l}\text { Retrospectiva } \\ \text { Informe } \\ \text { Horizon }\end{array} & \begin{array}{l}\text { Incorporación } \\ \text { tecnológica alusivas al Mobile Learning }\end{array} \\ 2006 & \text { El teléfono en tu bolsillo } \\ 2007 & \text { Teléfonos móviles } \\ 2008 & \text { Banda ancha móvil }\end{array}$

Previsión de su incorporación educativa por años

De 2 a 3 años

De 2 a 3 años

De 2 a 3 años

Vivat Academia. Revista de Comunicación. 15 diciembre 2020 /15 marzo 2021, n 153, 73-97 
Mascarell Palau, D.

Fomento del Mobile Learning en educación alrededor de la última década. Un estudio de caso en España través de una selección de aportaciones

$\begin{array}{lll}2009 & \text { Móviles } & \text { En } 1 \text { año o menos } \\ 2010 & \text { Ordenadores móviles } & \text { En } 1 \text { año o menos } \\ 2011 & \text { Móviles } & \text { En } 1 \text { año o menos } \\ 2012 & \text { App móviles } & \text { En } 1 \text { año o menos } \\ 2013 & \text { Tabletas digitales } & \text { En } 1 \text { año o menos } \\ 2014 & \text { Flipped Classroom (Metodología) } & \text { En } 1 \text { año o menos } \\ 2015 & \text { BYOD (Bring Your Own Device) } & \text { En } 1 \text { año o menos } \\ 2016 & \text { BYOD, Realidad virtual y aumentada } & \text { En } 1 \text { año o menos } \\ 2017 & \text { Mobile Learning, Tecnologías } & \text { En } 1 \text { año o menos } \\ & \text { Aprendizaje Adaptativo } & \\ 2018 & \text { Inteligencia artificial } & \text { De } 2 \text { a } 3 \text { años } \\ 2019 & \text { Aprendizaje Móvil o Mobile Learning } & \text { En } 1 \text { año o menos } \\ & \text { Tecnologías analíticas } & \\ & & \end{array}$

Fuente: Elaboración propia.

En los últimos tres a cinco años, identificamos estudios que afirman numerosos beneficios en el uso de los dispositivos móviles. Los contextos tecnológicos generan interacción hacia los contenidos educativos mediante las pantallas táctiles de los dispositivos móviles, según Cabero (2017), Villalustre y del Moral (2017). Por otro lado, estudios previos de Cubillo, Martín, Castro, \& Colmenar (2014); Kamphuis, Barsom, Schijven, \& Christoph, (2014); Solano, Sánchez, \& Recio, (2015) nos acercan a las aportaciones de la mejora en el aprendizaje colaborativo y aumento de participación de los estudiantes. En relación a los resultados vinculados a nuevos entornos de enseñanza-aprendizaje, generados por el aumento de la motivación y el gran interés en la participación en actividades, señalamos a Fombona y Pascual, (2017); Toledo \& Sánchez, (2017); Marín \& Muñoz, (2018).

En 2019, hacemos referencia a un estudio sobre el aprendizaje y la eficacia de la realidad aumentada en las aulas de infantil, con alumnado de 5 años y el uso de tabletas digitales. Según López, J. Pozo, S. y López, G. (2019) se demuestra y constata que las TIC propician el camino hacía el proceso de aprendizaje. A través de recursos innovadores los estudiantes son capaces de llevar a cabo diversas tareas, afianzar el aprendizaje y asimilar nuevos contenidos curriculares. Finalmente, concluyen que, en base a los resultados obtenidos "El uso de recursos didácticos innovadores mediante RA permite alcanzar altas valoraciones en la calificación, participación activa, autonomía, actitud, motivación, interés, atención y en los aprendizajes de carácter colaborativo, ubicuo, significativo y constructivista de los discentes", (p. 172).

La sensibilización de la comunidad educativa hacia la implementación del Mobile Learning y el uso de dispositivos móviles en las aulas depende en gran medida de enfocar el conocimiento de los futuros maestros hacia una educación emergente propia de la segunda mitad del siglo XXI con TIC. Por tanto, son necesarias experiencias con dispositivos móviles en el aula, con el fin de valorar el potencial didáctico de esta tecnología, empezando por las aulas de Magisterio del grado de Infantil. (Villalustre, 2020).

Vivat Academia. Revista de Comunicación. 15 diciembre 2020 /15 marzo 2021, nº 153, 73-97 
Fomento del Mobile Learning en educación alrededor de la última década. Un estudio de caso en España través de una selección de aportaciones

\section{DISCUSIÓN}

Es de interés el uso de los dispositivos móviles y, en concreto, de los smartphones, en los diferentes niveles y etapas de la educación formal, sobre todo en la enseñanza superior, como elemento omnipresente en la realidad social. Esta tecnología posibilita el enriquecimiento de la formación tanto en discentes como en docentes, enlazando y absorbiendo diferentes ramas de conocimiento, a través del aprovechamiento de las múltiples perspectivas educativas que ofrece. Los centros educativos comienzan a plantearse trabajar en la línea de esta metodología, aunque todavía en formas incipientes. Existen discrepancias por parte de la comunidad educativa respecto a su uso y sus límites, cuestiones que se deben abordar eficazmente. En cualquier caso, es inevitable en nuestra actualidad obviar la presencia y potencia educativa de estas herramientas.

Organismos como la Unesco y la Fundación Telefónica han apostado firmemente por la implementación pedagógica del Mobile Learning, a lo largo de los pasados años, a través de diversos proyectos. Entre ellos se distinguen, por su aportación social, los dirigidos a prestar apoyo a las comunidades más desfavorecidas del panorama nacional e internacional, con la premisa, entre otras, de generar avances en cuanto a la reducción de la brecha digital. Se ha constatado además un trabajo mutuo y coordinado, sobre todo en este último año, 2019, a través de la Semana Internacional del Mobile Learning. La comunidad científica ha desarrollado y sigue desarrollando paulatinamente, como señalan los datos aportados, un incremento sustancial de ensayos y análisis sobre el Mobile Learning como modalidad de trabajo educativo. Este ascenso colabora en arrojar luz sobre los beneficios e inconvenientes de su integración. También el Informe Horizon, uno de los más relevantes en cuanto a predicciones sobre las incorporaciones tecnológicas educativas, ha ido pronosticando alrededor de la última década, la omnipotente presencia ubicua de la tecnología portable, como herramienta de aprendizaje tanto fuera como dentro del aula, y en cualquier momento y lugar. De hecho, 2020 se prevé como el último año de su supuesta incorporación educativa. Recientes propuestas, como la Realidad Aumentada, Virtual y Mixta, contribuyen igualmente a la prolongación del uso de los dispositivos móviles en entornos didácticos.

\section{CONCLUSIONES}

Todos los actores citados, y muchos otros que lo sustentan, no abordados en este estudio por motivos obvios de espacio, avalan una realidad tecnológica que los educadores debemos contemplar y afrontar en la educación del siglo XXI. Como hemos podido comprobar, el aprendizaje en movilidad se vislumbra como una metodología emergente que se va implementando paulatinamente, aunque con discreción. La comunidad educativa, en el mejor de los casos, está dividida. Si bien existe cierta aceptación a su uso, a la vez subyacen connotaciones de rechazo. El debate está servido. Su incorporación en el aula es, de momento, a través de ensayos con experiencias educativas que tienen como objeto dar a conocer su potencial como herramienta de colaboración en el aprendizaje. A su vez, evaluar actitudes y 
Fomento del Mobile Learning en educación alrededor de la última década. Un estudio de caso en España través de una selección de aportaciones

prejuicios de los docentes y discentes. Por tanto, resultan de gran interés los estudios científicos que apelen a la investigación y profundicen en el marco educativo del aprendizaje móvil. Ahondar en determinados contextos y situaciones arrojará luz hacia el uso apropiado y sus beneficios. Hablamos de un dispositivo, el 92martphone, que se ha convertido en una extensión de nuestro cuerpo. La sociedad, a día de hoy, lo ha integrado como uno más de sus objetos personales portables, completamente imprescindible. Su ausencia genera ansiedad, conocida patológicamente como "nomofobia". La sociedad de la segunda mitad del siglo XXI ha mudado sus hábitos, encaminados a pasar más tiempo ante las pantallas móviles. Las imágenes que estas representan y que los y las jóvenes consumen a diario, colaboran al imaginario visual vinculado a la educación en artes.

Los cambios sociales y tecnológicos deben ser incorporados, con las adaptaciones oportunas, a nuestros procesos de enseñanza-aprendizaje. Una nueva manera de enseñar y aprender se está gestando, mediada por las TIC, y su desarrollo es imparable. Los docentes estamos abocados a adaptarnos a las circunstancias y metodologías que impliquen nuevas formas de enseñar y que cooperen en potenciar el estímulo de nuestros estudiantes, en tanto que resulten coherentes con su realidad tecnológica cotidiana. Solo así ofreceremos una educación acorde con nuestros tiempos, mediante nuestro modelo pedagógico.

\section{REFERENCIAS}

Bardin, L. (2002). Análisis de contenido. Tres Cantos. Madrid: Akal.

Botella, A., Hurtado, A. y Ramos, S. (2019). Innovación y TIC en el paisaje sonoro de la música festera a través de la creación de musicomovigramas. Vivat Academia. Revista de Comunicación 147, 109-123. doi: http://doi.org/10.15178/va.2019.147.109$\underline{123}$

Brazuelo, F. y Gallego, D. (2011). Mobile Learning. Los dispositivos móviles como recurso educativo. Sevilla: Mad Eduforma.

Brazuelo, F. y Gallego, D. (2014). Estado del Mobile Learning en España. Educar em Revista, 4. 99-128. Recuperado de http://www.scielo.br/pdf/er/nspe4/0101-4358er-esp-04-00099.pdf

Cabero, J. (2017). La formación en la era digital: ambientes enriquecidos por la tecnología. Revista Gestión de la Innovación en Educación Superior, 2(2), 41-64.

Camacho, M. (2011). Mobile Learning y el aprendizaje emergente en el ámbito educativo: retos y potencialidades. Infoeventos. Recuperado de https://es.slideshare.net/marcamacho/mobile-learning-y-aprendizaje-emergente

Castaño, C. \& Cabero, J. (Coords) (2013). Enseñar y Aprender en Entornos M-Learning. Madrid: Editorial Síntesis.

Vivat Academia. Revista de Comunicación. 15 diciembre 2020 /15 marzo 2021, nº 153, 73-97 
Fomento del Mobile Learning en educación alrededor de la última década. Un estudio de caso en España través de una selección de aportaciones

Cegos, Beyond knowledge. (2013). Estudio sobre la formación de los trabajadores en Europa (29/04/2013). Recuperado de https://www.cegos.es/actualidad/estudioformacion-trabajadores-europa

Cross, J. (2006). Informal Learning. San Francisco: Pfeiffer.

Cubillo, J., Martín, S., Castro, M. y Colmenar, C. (2014). Recursos digitales autónomos mediante realidad aumentada. RIED. Revista Iberoamericana de Educación a Distancia, 17(2), 241-274.

Fombona, J. y Pascual, M. Á. (2017). La producción científica sobre Realidad Aumentada, un análisis de la situación educativa desde la perspectiva SCOPUS. EDMETIC, 6(1), 39-61.

Fox, Virginia. (2005). Análisis documental de contenido: principios y prácticas. Buenos Aires: Alfagrama.

Fundación Telefónica. (2013). Guía Mobile Learning. Recuperado de https://www.telefonica.com/es/web/negocio-responsable/articulo/Lblogs/guia-mobile-learning-recursos-educativos-para-tu-smartphone

Fundación Telefónica. (2014). Laboratorio social. Mobile Learning. Mi móvil al servicio de la comunidad: aprender y compartir más allá del aula. Recuperado de https://www.fundaciontelefonica.com/cultura-digital/publicaciones/268/\#openModal

Fundación Telefónica. (2015). Disminuyendo la brecha digital en las comunidades rurales a través del Mobile Learning. Recuperado de https://profuturo.education/topics/disminuyendo-la-brecha-digital-en-lascomunidades-rurales-a-traves-del-mobile-learning/

Fundación Telefónica. (2016). Si lo vives, lo compartes. Cómo se comunican los jóvenes en un mundo digital. Recuperado de https://www.fundaciontelefonica.com/culturadigital/publicaciones/499/\#openModal

Fundación Telefónica. (2019). ProFuturo. Recuperado de https://www.fundaciontelefonica.com/educacion_innovacion/profuturo/

Hinojo, F., Aznar, I. y Romero, J. (2018). Dispositivos móviles para el aprendizaje: análisis de la investigación doctoral sobre Mobile Learning en España. Revista Texto Livre: Linguagem e Tecnologia, 11(3), 154-175. Recuperado de http:// www.periodicos.letras.ufmg.br/index.php/textolivre/article/view/13743

Informe Horizon. (2010). Primaria, Secundaria y Enseñanza Universitaria. (k-12 edition). Recuperado 
Mascarell Palau, D.

Fomento del Mobile Learning en educación alrededor de la última década. Un estudio de caso en España través de una selección de aportaciones

http://recursostic.educacion.es/blogs/europa/media/blogs/europa/informes/R esumen_ITE_Informes_Horizon_2010.pdf

Informe Horizon. (2013). Enseñanza universitaria. Tecnologías de 1 a 5 años. Recuperado de https://intef.es/Noticias/informe-horizon-2013-ensenanza-universitariatecnologias-de-1-a-5-anos/

Informe Horizon. (2017). Enseñanza Universitaria. Tecnologías emergentes. Recuperado de https://intef.es/Noticias/informe-horizon-2017-ensenanzauniversitaria-tecnologias-emergentes/

Informe Horizon. (2019). Educación Superior. Recuperado de https://intef.es/Noticias/resumen-informe-horizon-2019/

Instituto Nacional de Estadística. (2018). España en cifras 2018. Recuperado de https://www.ine.es/prodyser/espa_cifras/2018/

Kamphuis, C., Barsom, E., Schijven, M. \& Christoph, N. (2014). Augmented reality in medical education?. Perspectives on medical education, 3(4), 300-311.

Laouris, Y. \& Eteokleous, N. (2005). We need an Educationally Relevant Definition of Mobile Learning. In mLearn 2005 - 4th World conference on mLearning Cape Town, South Africa. Recuperado de http:/ / citeseerx.ist.psu.edu/viewdoc/download?doi=10.1.1.106.9650\&rep=rep1\&t ype $=$ pdf

Mascarell, D. (2012). Las TIC como recurso de ataque ante la pedagogía tóxica en el área de Didáctica de la Expresión Plástica y Visual de la Escuela de Magisterio Ausiàs March de València. Resumen del III Congreso Europeo de Tecnologias de la Información en la Educación y en la Sociedad: Una visión crítica, 209-211. Recuperado de

https://www.academia.edu/3693129/Mascarell_Palau_D._2012_._Las_TIC_como recurso_de_ataque_ante_la_pedagog $\% \mathrm{C} 3 \% \mathrm{ADa} t \mathrm{t} \% \mathrm{C} 3 \% \mathrm{~B} 3 x \mathrm{c}$ a_en_el_\%C3\% A1re a_de_Did $\%$ C3\%A1ctica_de_la_Expresi $\%$ C3\%B3n_Pl\%C3\%A1stica_y_Visual_de_la Escuela_de_Magisterio_Ausi\%C3\%A0s_March_de_Valencia._P\%C3\%A1g._209

Mascarell, D. (2013). "Salvem el Cabanyal". Alumnado de Magisterio produce Cultura Visual a través de sus teléfonos móviles. En (Edarte, Grupo de investigación, 2013) Investigar con jóvenes: ¿Qué sabemos de los jóvenes como productores de Cultura Visual?, 233-243. Pamplona: Pamiela - Edarte (UPNA/NUP). Recuperado de http://academica-e.unavarra.es/handle/2454/19800

Mascarell, D. (2017). Dispositius mòbils com a nous entorns d'aprenentatge. Contextos emergents en les arts visuals. En (Huerta i Alonso-Sanz, 2017), Nous entorns d'aprenentatge per a les arts i la cultura, 147-158. Valencia: Tirant Humanidades. 
Mascarell Palau, D.

Fomento del Mobile Learning en educación alrededor de la última década. Un estudio de caso en España través de una selección de aportaciones

Mascarell Palau, S. D. (2019). Implementación y uso de las TIC. Dispositivos móviles en educación en Artes. Un estado de la cuestión. Revista de Comunicación de la SEECI, 50, 73-86. doi: $\underline{10.15198 / \text { seeci.2019.50.73-86 }}$

Mobile Word Capital. (2019). mSchools. Una nueva forma de enseñar y aprender. Recuperado de https://mschools.mobileworldcapital.com/es/resources-teachersschools-2/

Peña, T. \& Pirela Morillo, J. (2007). La complejidad del análisis documental. Revista Información, Cultura y Sociedad, 16, 55-81. Recuperado de https://bit.ly/2kziGYg

Rinaldi, M. (2011). Revolución Mobile Learning. Spain: Lulo Bubok. Recuperado de http:/ / es.slideshare.net/brunounix/a-revoluo-do-mobile-learning

Santacana, J. y Coma, L. (coords.) (2014). El mLearning y la educación patrimonial. Austurias: Trea.

Santiago, R., Amo, D. \& Díez, A. (2014). ¿Pueden las aplicaciones educativas de los dispositivos móviles ayudar al desarrollo de las inteligencias múltiples? EDUTEC, Revista Electrónica de Tecnología. Educativa, 47. Recuperado de https://www.edutec.es/revista/index.php/edutec-e/article/view/63

Scopeo, Observatorio de la Formación en Red. (2011). MLearning, en España, Portugal y America Latina. Novembre de 2011. Monográfico SCOPEO, 3. Recuperado de http://www.educoas.org/portal/la_educacion_digital/147/pdf/spain.pdf

Sharples, M., Taylor, J. \& Vavoula, G. (2005). Towards a theory of mobile learning. Recuperado de https://www.researchgate.net/publication/228346088

II Simposio Internacional sobre Mobile Learning. (2014). Repensando la Escuela y el Aprendizaje. Aprendizaje Móvil. (Córdoba). Recuperado de http://www.simposioml.org/simposio-2014/

III Simposio Internacional sobre Mobile Learning. (2015). Diseñando proyectos pedagógicos para el Mobile Learning: Claves para el aprendizaje en la escuela. (Madrid). 2015. Recuperado de http://www.simposioml.org/conclusiones-simposio-ml$\underline{2015 /}$

V Simposio Internacional sobre Mobile Learning. (2017). El Mobile Learning como herramienta para la mejora de elementos clave en la educación: la evaluación. (Valencia). Recuperado de https://www.colegiomascamarena.es/colegio-acoge-iv-simposiomobile-learning-maecenas-educacion/

Solano, I. M., Sánchez, M. M. y Recio, S. (2015). El vídeo en Educación infantil: Una experiencia colaborativa entre Infantil y Universidad para la alfabetización digital. RELAdEI. Revista Latinoamericana de Educación Infantil, 4(2), 181-201. 
Fomento del Mobile Learning en educación alrededor de la última década. Un estudio de caso en España través de una selección de aportaciones

Solís, H. A. (2003). El análisis documental como eslabón para la recuperación de información y los servicios. Recuperado de http:// www.monografias.com/trabajos14/analisisdocum/analisisdocum.shtml

Traxler, J. (2009). Learning in the Mobile Age. International Journal of Mobile and Blended Learning, 1, 1-12. Recuperado de https://www.academia.edu/171500/Learning_in_a_Mobile_Age

UNESCO. (2013). Semana de la UNESCO del aprendizaje mediante dispositivos móviles, 2013. París: UNESCO. Recuperado de http://www.unesco.org/new/es/unesco/themes/icts/m4ed/unesco-mobilelearning-week/\#topPage

UNESCO. (2016). Informe de Seguimiento de la Educación en el Mundo, 2016: La Educación al servicio de los pueblos y el planeta: creación de futuros sostenibles para todos. París: UNESCO. Recuperado de https://unesdoc.unesco.org/ark:/48223/pf0000248526

UNESCO. (2017). Supporting teachers with mobile technology. Lessons drawn from unesco projects in Mexico, Nigeria, Pakistan and Senegal. París: UNESCO. Recuperado de http://unesdoc.unesco.org/images/0025/002515/251511e.pdf

UNESCO. (2018). Skills for a connected world: report of the UNESCO Mobile Learning Week 2018, 26-30 March. París: UNESCO. Recuperado de https://unesdoc.unesco.org/ark:/48223/pf0000265893

UNESCO. (2019). Artificial intelligence for Sustainable Development: synthesis report, Mobile Learning Week 2019. París: UNESCO. Recuperado de https://unesdoc.unesco.org/ark:/48223/pf0000370308

Vavoula y Sharples. (2008). Challenges in Evaluating Mobile Learning. Published in Proceedings of Mlearn, 1-8. Recuperado de https://leicester.figshare.com/articles/conference_contribution/Challenges_in_Ev aluating_Mobile_Learning/10096823/1

Villalustre Martínez, L. (2020). Propuesta metodológica para la integración didáctica de la realidad aumentada en Educación Infantil. EDMETIC, 9(1), 170-187. doi: $\underline{10.21071 / \text { edmetic.v9i1.11569 }}$

Villalustre, L. y del Moral, M. E. (2017). Juegos perceptivos con realidad aumentada para trabajar contenido científico. Educação, Formação \& Tecnologias, 10(1), 36-46.

\section{AUTOR}




\section{Mascarell Palau, D.}

Fomento del Mobile Learning en educación alrededor de la última década. Un estudio de caso en España través de una selección de aportaciones

\section{David Mascarell Palau}

Profesor doctor asociado de Educación Artística en la Facultad de Magisterio de la Universidad de Valencia, España, desde 2010. Especialista en TIC y en concreto sobre la metodología Mobile Leaning o aprendizaje en movilidad. Ha realizado diversas publicaciones en revistas y capítulos de libro, así como impartido talleres y cursos en centros de formación del profesorado. Forma parte del grupo de investigación en Pedagogías Culturales, Creari (GIUV2013-103). Recientemente ha sido invitado en la Oslo Metropolitan University, Noruega, dando a conocer esta modalidad de aprendizaje acorde con la era de las pantallas móviles del siglo XXI.

David.Mascarell.Palau@uv.es

Academia.edu: https://uv.academia.edu/DavidMascarell 